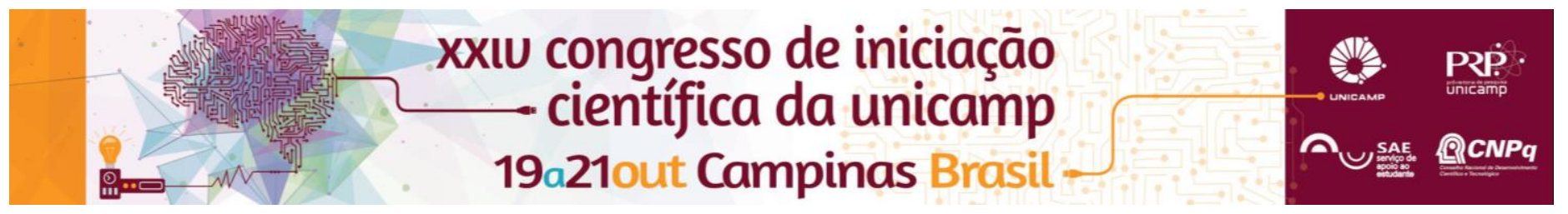

\title{
Minimizing Ambiguities and Duplicity in Scrum Stories.
}

\section{Fernanda Bertola Luiz*, Ana Estela Antunes da Silva.}

\begin{abstract}
When working with natural language it is very common to find different meanings to the same word, this way, to minimize ambiguities and duplicity in a sentence, is necessary to work with the concept of similarity. This project propose the analysis of users stories of Scrum to find the best similarity algorithm to reduce multiples meanings of a sentence.
\end{abstract}

\section{Key words:}

Similarity, ambiguity and duplicity, natural language.

\section{Introduction}

Agile methodology for software development is one of the most useful resource to delivery a project in an effective and flexible way. This work propose analyze similarity algorithms capables of verify Scrum stories semantically and reduce or eliminate ambiguities or duplicity found in the stories.

Research already been made in Natural Language Processing (NLP) field, this way, the results of the project is to offer support to decision making to verify if Scrum stories does not contain duplicity and their ambiguities minimized.

\section{Results and Discussion}

To design the study, was used WS4J1 ${ }^{1}$ (WordNet Similarity for Java), that is an online Java-API that has a set of semantic similarity algorithms, and to quantify the tests results, was used a user stories base, from the University of Bath². From the set of algorithms, was chose the WuP algorithm ${ }^{3}$ and Lin algorithm ${ }^{4}$, separately, to see the sentences as their semantic similarities. From the stories base was chose two sentences to exemplify the results, the sentences are "As a depositor I want to deposit and maintain datasets through a simple web interface", as sentence 1, and "As a depositor I want to have a user interface that is familiar to me", as sentence 2.

While calculating the similarity between sentences, the tool displays the results in a matrix with the score between the words of the sentences, where the value can range from 0 to 1 ( 0 means that words have no semantic relationship and one means that words are identical).

When relating the two user stories, only 18 from the 225 pairs of words are considered as valid, and therefore punctuated, this way, the tables bellow only show the 18 valid pairs.

\begin{tabular}{|c|c|c|c|c|c|c|}
\hline & $\begin{array}{c}\text { deposit } \\
\text { or }\end{array}$ & want & deposit & $\begin{array}{c}\text { maintai } \\
n\end{array}$ & web & $\begin{array}{c}\text { interfac } \\
\text { e }\end{array}$ \\
\hline $\begin{array}{c}\text { deposit } \\
\text { or }\end{array}$ & 1.0000 & - & - & - & 0.5263 & 0.4348 \\
\hline want & - & 1.0000 & 0.3333 & 0.5000 & - & - \\
\hline have & - & 0.5714 & 0.3636 & 0.8000 & - & - \\
\hline user & 0.8000 & - & - & - & 0.5882 & 0.4762 \\
\hline $\begin{array}{c}\text { interfac } \\
\text { e }\end{array}$ & 0.4348 & - & - & - & 0.7273 & 1.0000 \\
\hline is & - & 0.8000 & 0.3333 & 0.5000 & - & - \\
\hline
\end{tabular}

Table 1. Partial result matrix using WuP algorithm. DOI: 10.19146/pibic-2016-50919

\begin{tabular}{|c|c|c|c|c|c|c|}
\hline $\begin{array}{c}\text { deposit } \\
\text { or }\end{array}$ & want & deposit & $\begin{array}{c}\text { maintai } \\
n\end{array}$ & web & $\begin{array}{c}\text { interfac } \\
\text { e }\end{array}$ \\
\hline $\begin{array}{c}\text { deposit } \\
\text { or }\end{array}$ & 1.0000 & - & - & - & 0.1221 & 0.1067 \\
\hline want & - & 1.0000 & 0.3186 & 0.000 & - & - \\
\hline have & - & 0.2481 & 0.5483 & 0.6908 & - & - \\
\hline user & 0.1977 & - & - & - & 0.1509 & 0.1325 \\
\hline $\begin{array}{c}\text { interfac } \\
\text { e }\end{array}$ & 0.1067 & - & - & - & 0.1123 & 1.0000 \\
\hline is & - & 0.4524 & 0.0000 & 0.0000 & - & - \\
\hline
\end{tabular}

Table 2. Partial result matrix using Lin algorithm.

Despite WS4J tool does not have the test result in an overall score for the similarity between sentences, but only by word by word, through the tables above it is possible to see that the WuP algorithm has a more satisfactory result. In addition to not have any score with the minimum value (zero), the algorithm was able to identify the semantic similarity between the context "a simple web interface" of sentence 1 , with the context "user interface que is familiar to me" of sentence 2 .

\section{Conclusions}

The algorithms chosen for study showed to be promising in their purposes, as both calculate and quantify the semantic similarity between words. The main difference between the algorithms is that WuP algorithm works with synonyms and sets of words, while Lin algorithm works with quantification of data, characterizing it as a statistical model. This work was able to study and analyze results of comparison between pairs of stories with semantic similarity algorithms. Such algorithms, particularly the WuP, have the potential to be used as technique of measure for possible duplicate stories.

\section{Acknowledgement}

I would like to express my special thanks of gratitude to my guiding teacher, Ana Estela Antunes da Silva, who always encouraged me to be and achieve the best I could. She gave the opportunity to do this project and always believed in me.

1Shima, H. Project WordNet Similarity for Java. 2011 https://code.google.com/p/ws4j/. Accessed on December 18, 2015.

${ }^{2}$ Cope, J. Institutional Data Repository User Stories. 2013, http://opus.bath.ac.uk/34082/. Accessed on November 18, 2015.

${ }^{3} \mathrm{Wu}, \mathrm{Z}$; Palmer, M. Verb semantics and lexical selection. 1994, 133-138.

${ }^{4}$ Lin, D. An information-theoretic definition of similarity. 1998, 296-304. 